STUDI

FRANCESI

\section{Studi Francesi}

Rivista quadrimestrale fondata da Franco Simone

170 (LVII | II) | 2013

Varia

\title{
La Recherche dix-huitiémiste en France et en Pologne. Bilan et perspectives, Izabella Zatorska (éd.)
}

\section{Regina Bochenek-Franczakowa}

\section{(2) OpenEdition}

1 Journals

\section{Édition électronique}

URL : https://journals.openedition.org/studifrancesi/3099

DOI : 10.4000/studifrancesi.3099

ISSN : 2421-5856

Éditeur

Rosenberg \& Sellier

\section{Édition imprimée}

Date de publication : 1 juillet 2013

Pagination : 456-457

ISSN : 0039-2944

\section{Référence électronique}

Regina Bochenek-Franczakowa, «La Recherche dix-huitiémiste en France et en Pologne. Bilan et

perspectives, Izabella Zatorska (éd.) », Studi Francesi [En ligne], 170 (LVII | II) | 2013, mis en ligne le 30 novembre 2015, consulté le 02 février 2023. URL : http://journals.openedition.org/studifrancesi/3099 ; DOI : https://doi.org/10.4000/studifrancesi.3099

Ce document a été généré automatiquement le 2 février 2023.

\section{(c) (i) (3)}

Creative Commons - Attribution - Pas d'Utilisation Commerciale - Pas de Modification 4.0 International - CC BY-NC-ND 4.0

https://creativecommons.org/licenses/by-nc-nd/4.0/ 


\title{
La Recherche dix-huitiémiste en France et en Pologne. Bilan et perspectives, Izabella Zatorska (éd.)
}

\author{
Regina Bochenek-Franczakowa
}

\section{RÉFÉRENCE}

La Recherche dix-huitiémiste en France et en Pologne. Bilan et perspectives, Izabella ZATORSKA

(éd.), Varsovie, 2012, pp. 141.

1 Cet ouvrage est consacré à la mémoire de l'éminente chercheuse polonaise Ewa Rzadkowska, professeur de l'Université de Varsovie, disparue en 2009. Initiatrice de la journée d'étude et rédactrice du volume, I. Zatorska brosse d'abord la silhouette d'Ewa Rzadkowska et fait une brève synthèse de ses travaux, tous consacrés à la littérature française du xvIII ${ }^{\mathrm{e}}$ siècle. Ce portrait est complété par deux témoignages chaleureux, de la plume des critiques universitaires qui ont connu Mme Rzadkowska en personne, Jean Ehrard et Dominique Triaire. Les études contenues dans cet ouvrage portent sur divers problèmes des recherches dix-huitiémistes en France et en Pologne. Michel DELON propose de considérer le roman français du début du XIX ${ }^{e}$ siècle dans la perspective du double mouvement de dérégulation et de normalisation du genre. L'A. a raison d'attirer l'attention sur cette tendance du roman, encore peu étudiée, qui se manifeste par la "chapitration» de la narration et une sorte d'objectivation des descriptions des paysages (Le Roman en 1800. Entre dérégulation et normalisation, pp. 19-39). Deux études forment la partie «Regards diachroniques»: Maciej ABRAMOwICZ juxtapose les belles lettres de deux époques par le biais des stratégies de véridiction lesquelles découvrent des points communs, indépendamment de leurs déterminants historiques ( $L a$ Véridiction dans la littérature médiévale et celle du XVIII ${ }^{e}$ siècle, pp. 43-51). Joanna z'UROWSKA cherche dans l'œuvre de Marcel Proust certaines traces des Mémoires de Saint-Simon, sur l'exemple de la tante Léonie et celui du salon de la duchesse de Guermantes (Proust 
et Saint-Simon, pp. 53-65). La seconde partie intitulée «Regards transculturels» est constituée par cinq études. Anna GRZESKOWIAK-KRWAWICZ analyse les conceptions de Rousseau proposées dans ses Considérations sur le Gouvernement de Pologne en confrontation avec les idéaux politiques des aristocrates polonais de l'époque, sur l'exemple du Tableau du gouvernement de Pologne de Michał Wielhorski (Rousseau et la Pologne, pp. 69-78). Paweł MATYASZEWSKI, présentant l'état de recherches polonaises sur Montesquieu, s'étonne à juste titre du trop faible intérêt porté aux œuvres littéraires du grand écrivain des Lumières, dont la présence, en Pologne, est presque exclusivement réservée au domaine de la pensée juridique (Montesquieu en Pologne, pp. 79-91). Marian SKRZYPEK attire l'attention sur une source du motif romantique de «brigand généreux»: celle puisée dans certains écrits philosophiques de Diderot (Diderot parmi les honnêtes brigands et les filibustiers, pp. 93-104). Marzena CHROBAK met en lumière les problèmes auxquels se heurtaient les traducteurs polonais $\mathrm{du} \mathrm{XVIII}^{\mathrm{e}}$ siècle, notamment s'il s'agit des toponymes urbains (Paris et la Pologne. L'Image de Paris dans le roman français $d u X^{X} I I e^{e}$ siècle et dans ses traductions polonaises, pp. 105-115). Jadwiga WARCHOŁ démontre l'importance de la traduction de Zadig de Voltaire pour le plus grand roman polonais des Lumières, Les Aventures de Nicolas Dos'wiadczyn'ski d'Ignacy Krasicki (La Continuité de la tradition romanesque en Pologne au XVIII siècle à la lumière des traductions, pp. 117-132). Le volume est clos par un bref aperçu qui ouvre les perspectives possibles des recherches dix-huitiémistes en Pologne (I. ZATORSKA, Nos perspectives, pp. 133-134). 